Bangladesh J.PI. Breed. Genet., 23(1):13-18, 2010

\title{
CHARACTER ASSOCIATION AND PATH ANALYSIS OF EXOTIC TOMATO (Solanum lycopersicum L.) GENOTYPES
}

\author{
B. M. R. Islam, N. A. Ivy, M. G. Rasul and M. Zakaria ${ }^{1}$ \\ Department of Genetics and Plant Breeding \\ Bangbandhu Sheikh Mujibur Rahman Agricultural University \\ Gazipur 1706, Bangladesh
}

\begin{abstract}
Correlations and path coefficient were studied in 39 exotic tomato (Solanum lycopersicum L.) genotypes for nine yield contributing characters. The correlation coefficients were determined to find out the inter relationship among the characters studied. Yield per plant was found highly significant and positively correlated with flowers per plant, fruits per plant, fruit length, fruit diameter and individual fruit weight which indicated that yield could be increased by improving a traits. In order to obtain a clear picture of the inter relationship between yield per plant and its components, direct and indirect effects were measured using path coefficient analysis. Fruits per plant showed the highest positive direct effect $(0.980)$ on yield per plant followed by individual fruit weight (0.958). On the other hand, the highest negative direct effect on yield per plant showed by days to first flowering $(-0.277)$ followed by fruit length (-0.141). The characters showed high direct effect on yield per plant indicated that direct selection for these traits might be effective and there is a possibility of improving yield per plant through selection based on these characters. Residual effect was considerably low (0.183) which indicated that characters included in this study explained almost all variability towards yield.
\end{abstract}

Keywords: Correlation coefficients, path coefficient analysis, residual effect

\section{INTRODUCTION}

Tomato (Solanum lycopersicum L.) is one of the most important and popular vegetables in the world. It belongs to the family Solanaceae with chromosome number $2 n=24$ (Jenkins, 1948) and is normally a self pollinated annual crop. Many developing countries like Bangladesh benefited from the green revolution in cereal production in the past but were not able to substantially reduce poverty and malnutrition. Vegetable production can help farmers generate income which eventually alleviate poverty. Tomato is one of the most important vegetables in terms of acreage, production, yield, commercial use and consumption. At present $6.10 \%$ cultivable land area (48,538 acres) is under tomato cultivation both in winter and summer (BBS, 2008). It is cultivated all over the country due to its adaptability to wide range of soil and climate (Ahmed, 1976). It is the most consumable vegetable crop after potato and sweet potato occupying the top of the list of canned vegetable (Chowdhury, 1979). Tomatoes are used directly as raw vegetables in sandwiches and salads. Several processed items like paste, puree, soup, pickles, ketchup, jelly, juices, drinks, whole peeled tomatoes, etc. are prepared on a large

\footnotetext{
1 Department of Horticulture, Bangbandhu Sheikh Mujibur Rahman Agricultural University, Gazipur 1706, Bangladesh
} 
scale and enjoy high acceptance as food ingredients. Tomato is an important source of vitamin A, B, C and other nutrient element. During ripening, there is a 500 fold increase in the level of lycopene in tomato fruit (Bai and Lindhot, 2007). Increased lycopene has proven nutritional value as an antioxidant that is associated with a low incidence of certain forms of human cancer (Bai and Lindhot, 2007). The degree of association between characters as indicated by the correlation coefficients has always been a helpful instrument for the selection of desirable characters under a breeding program. Like other crops, yield of tomato is the final product attributed by a complex chain of interrelating effects of different characters (Singh et al., 1989; Islam and Khan, 1991). So it is essential to make a comparative study among important characters to select desirable ones. Correlation coefficient alone cannot give a complete picture of the causal basis of relationship. Under such circumstances, path coefficient analysis is an effective tool (Islam and Khan, 1991 and McGiffen et al., 1994). Therefore present investigation was undertaken to estimate associations among desired traits and their direct and indirect contributions toward yield.

\section{MATERIALS AND METHODS}

The experiment was conducted at the experimental field of Department of Genetics and Plant Breeding, Bangabandhu Sheikh Mujibur Rahman Agricultural University (BSMRAU), Gazipur during winter season (October 2008 to March 2009) on an upland soil. The experimental site was situated in the sub tropical climate zone, characterized by heavy rainfall during the months from May to September and scanty rainfall in the rest of the year. Seeds of $F_{2}$ segregating generation of 39 exotic tomato genotypes were used as experimental materials and collected from the Genetics and Plant Breeding Department. The recommended doses of fertilizers such as cowdung $9 \mathrm{t} / \mathrm{ha}$, Urea (550 kg/ha), TSP (450 kg/ha) and MP (200 kg/ha) were applied during cultivation. The experiment was conducted using Randomized Complete Block Design (RCBD) with three replications. Genotypic and phenotypic correlation coefficients were calculated according to the formula suggested by Johnson et al. (1955) and Hanson et al. (1956). Correlation coefficient were further partitioned into components of direct and indirect effects by path coefficient analysis originally developed by Wright (1921) and later described by Dewey and Lu (1959).

\section{RESULTS AND DISCUSSION}

\section{Correlation coefficients analysis}

Estimates of phenotypic and genotypic correlation coefficient between yield and its nine component characters in all possible combinations are presented in Table 1. In general, the genotypic correlation coefficients were considerably higher than the phenotypic ones. The result indicated a fairly strong inherent association between the characters studied. Days to first flowering showed positive significant genotypic correlation with flowers per plant (0.361), pericarp thickness (0.543) and fruits per plant (0.334), positive insignificant correlation with plant height at first harvest $(0.214)$, branches per plant (0.293) and yield per plant (0.160). The phenotypic correlation was insignificant for all the characters. Flowers per plant showed positive significant genotypic correlation with fruits per plant (0.999), fruit length (0.463) and yield per plant (0.786), positive insignificant correlation with plant height at first harvest (0.146), branches per plant (0.117), pericarp thickness (0.103) and negative insignificant correlation with fruit diameter $(-0.143)$ and individual fruit weight $(-0.293)$, whereas 
insignificant correlation was observed for all the characters at phenotypic level except positive significant corelation with flowers per plant (0.387). Plant height at first harvest showed positive significant correlation both at genotypic and phenotypic level with branches per plant $(0.515,0.359)$ and flowers per plant $(0.533,0.459)$. The results indicated that as the plant height increases the branches per plant and flowers per plant would increase.

Table 1. Genotypic $\left(r_{g}\right)$ and phenotypic $\left(r_{p}\right)$ correlation coefficients among nine yield related characters in 39 exotic tomato genotypes

\begin{tabular}{|c|c|c|c|c|c|c|c|c|c|c|}
\hline Characters & & FLPP & $\overline{\mathrm{PHFH}}$ & $\overline{B P P}$ & $\overline{\mathrm{PT}}$ & FPP & FL & FD & IFW & YPP \\
\hline \multirow{2}{*}{ DFFL } & $r_{g}$ & $0.361 *$ & 0.214 & 0.239 & $0.543^{* *}$ & $0.334^{*}$ & -0.033 & -0.136 & -0.221 & 0.160 \\
\hline & $r_{p}$ & 0.298 & 0.212 & 0.117 & 0.103 & 0.253 & 0.082 & 0.029 & -0.102 & 0.181 \\
\hline \multirow{2}{*}{ FLPP } & $r_{g}$ & & 0.146 & 0.727 & 0.026 & $0.999 * *$ & $0.463 * *$ & -0.143 & -0.294 & $0.786^{* *}$ \\
\hline & $r_{p}$ & & 0.080 & 0.200 & -0.016 & $0.387 *$ & -0.018 & -0.018 & -0.067 & 0.291 \\
\hline \multirow{2}{*}{ PHFH } & $r_{g}$ & & & $0.515^{* *}$ & -0.115 & $0.533 * *$ & $-0.629 * *$ & $-0.501 * *$ & $-0.500 * *$ & 0.086 \\
\hline & $r_{p}$ & & & $0.359 *$ & 0.001 & $0.459 * *$ & -0.086 & -0.182 & -0.279 & 0.180 \\
\hline \multirow{2}{*}{ BPP } & $r_{g}$ & & & & -0.225 & $0.490 * *$ & $-0.509 * *$ & $-0.474 * *$ & $-0.414 * *$ & 0.161 \\
\hline & $r_{p}$ & & & & -0.054 & $0.390^{*}$ & -0.082 & -0.044 & -0.227 & 0.164 \\
\hline \multirow{2}{*}{ PT } & $r_{g}$ & & & & & -0.013 & 0.271 & -0.155 & 0.002 & 0.169 \\
\hline & $r_{p}$ & & & & & 0.099 & $0.335^{*}$ & 0.040 & 0.081 & 0.188 \\
\hline \multirow{2}{*}{ FPP } & $r_{g}$ & & & & & & -0.273 & $-0.446 * *$ & $-0.681 * *$ & $0.468 * *$ \\
\hline & $r_{p}$ & & & & & & -0.022 & -0.259 & $-0.436^{* *}$ & $0.470^{* *}$ \\
\hline \multirow{2}{*}{ FL } & $r_{g}$ & & & & & & & $0.847 * *$ & $0.923^{* *}$ & $0.788 * *$ \\
\hline & $r_{p}$ & & & & & & & $0.472 * *$ & $0.512 * *$ & $0.441 * *$ \\
\hline \multirow{2}{*}{ FD } & $r_{g}$ & & & & & & & & $0.999 * *$ & $0.485^{* *}$ \\
\hline & $\mathrm{r}_{\mathrm{p}}$ & & & & & & & & $0.757 * *$ & $0.428 * *$ \\
\hline \multirow{2}{*}{ IFW } & $r_{g}$ & & & & & & & & & $0.306^{*}$ \\
\hline & $\mathrm{r}_{\mathrm{p}}$ & & & & & & & & & $0.408 * *$ \\
\hline
\end{tabular}

$* \mathrm{P}<0.05, * * \mathrm{P}<0.01$

DFFL - Days to first flowering (DAS), FLPP - Flowers per plant, PHFH - Plant height at first harvest $(\mathrm{cm})$, BPP - Branches per plant, PT - Pericarp thickness (mm), FPP - Fruits per plant, FL - Fruit length $(\mathrm{mm})$, FD - Fruit diameter $(\mathrm{mm})$, IFW - Individual fruit weight $(\mathrm{g})$ and YPP Yield per plant $(\mathrm{Kg})$

Plant height at first harvest showed negative significant genotypic correlation with fruit length (-0.629), fruit diameter $(-0.501)$ and individual fruit weight $(-0.501)$ indicated that as the plant height increases, fruit length, fruit diameter and individual fruit weight would decrease. Branches per plant showed positive significant correlation both at genotypic and phenotypic level with flowers per plant $(0.490,0.390)$ indicated that as the number of branches per plant increases, the number of fruits per plant increase. Branches per plant showed negative significant genotypic correlation with fruit length ($0.590)$, fruit diameter $(-0.474)$ and individual fruit weight $(-0.414)$ indicated that as the number of branches per plant increases, fruit length, fruit diameter and individual fruit weight would decrease. Pericarp thickness showed positive significant correlation with flowers per plant (0.390) at phenotypic level. Fruits per plant showed positive significant correlation both at genotypic and phenotypic level with yield per plant $(0.468,0.470)$, which indicated that as the number of fruits increases, the yield per plant would increase. Fruits per plant showed negative significant correlation (both genotypic and phenotypic level) with individual fruit weight $(-0.681,-0.436)$, which indicated that as the number of fruits increases, the individual fruit weight would decreases. Fruits per plant showed negative significant correlation with fruit diameter $(-0.446)$ at genotypic level, which indicated that as the number of fruits increases; the fruit diameter would decreases. Singh et al. (1997), Harer et al. (2003) and Haydar et al. (2007) reported that yield had a strong positive correlation with fruits per plant. Fruit length showed positive significant correlation both at genotypic and phenotypic level with fruit diameter $(0.847,0.472)$, 
individual fruit weight $(0.923,0.512)$ and yield per plant $(0.788,0441)$, which indicated that as the length of fruits increases, the fruit diameter, individual fruit weight and yield per plant would increase. Fruit diameter showed positive significant correlation both at genotypic and phenotypic level with individual fruit weight $(0.999,0.757)$, and yield per plant $(0.485,0.428)$ which indicated that as the diameter of fruits increases; the individual fruit weight and yield per plant would increase. Prasad and Rai (1999) and Agong et al. (2008) reported very high and significant correlation coefficient between yield and fruit length and fruit diameter. Individual fruit weight showed positive significant correlation both at genotypic and phenotypic level with yield per plant $(0.306$, 0.408 ) which indicated that as the individual fruit weight increases' the yield per plant would increase. Prasad and Rai (1999), Mohanthy (2002a and 2002b) and Harer et al. (2003) reported very high and significant correlation coefficient between yield and fruit weight.

\section{Path coefficient analysis}

Estimates of direct and indirect effects of causal variables were worked out using path coefficient analysis and the results are presented in Table 2. In path coefficient analysis days to first flowering showed negative direct effect $(-0.277)$ on yield per plant. The indirect effects via flowers per plant, plant height at first flowering, branches per plant, pericarp thickness, fruits per plant and fruit length were positive and via fruit diameter and individual fruit weight were negative. Indirect effect via fruit length was very poor. Positive correlation $(0.160)$ between days to first flowering and yield per plant was the cumulative contribution of these direct and indirect effects. Flowers per plant had positive direct effect $(0.211)$ on yield per plant. The indirect effects via plant height at first flowering, branches per plant, thickness of the pericarp and flowers per plant were positive and via days to first flowering, fruit diameter and individual fruit weight were negative. Positive significant correlation (0.786) between flowers per plant and yield per plant was the cumulative contribution of these direct and indirect effects.

Table 2. Partitioning genotypic correlation into direct (bold) and indirect effects of nine characters on yield per plant in 39 exotic tomato genotypes

\begin{tabular}{|c|c|c|c|c|c|c|c|c|c|c|}
\hline & DFFL & FLPP & PHFH & BPP & PT & FPP & FL & FD & IFW & $\begin{array}{l}\text { Genotypic } \\
\text { correlation } \\
\text { with yield }\end{array}$ \\
\hline DFFL & -0.277 & 0.076 & 0.024 & 0.016 & 0.232 & 0.328 & 0.005 & -0.031 & -0.211 & 0.160 \\
\hline FLPP & -0.100 & 0.211 & 0.016 & 0.048 & 0.011 & 0.979 & -0.065 & -0.033 & -0.282 & $0.786^{* * *}$ \\
\hline PHFH & -0.059 & 0.031 & 0.112 & 0.034 & -0.049 & 0.522 & 0.089 & -0.115 & -0.479 & 0.086 \\
\hline BPP & -0.066 & 0.153 & 0.057 & 0.067 & -0.096 & 0.480 & 0.072 & -0.109 & -0.396 & 0.162 \\
\hline PT & -0.150 & 0.006 & -0.013 & -0.015 & 0.426 & -0.013 & -0.038 & -0.036 & 0.002 & 0.169 \\
\hline FPP & -0.093 & 0.211 & 0.059 & 0.033 & -0.005 & 0.980 & 0.038 & -0.103 & -0.653 & $0.468 * *$ \\
\hline FL & 0.009 & 0.098 & -0.070 & -0.034 & 0.115 & -0.267 & -0.141 & 0.195 & 0.884 & $0.788 * *$ \\
\hline FD & 0.038 & -0.030 & -0.056 & -0.032 & -0.066 & -0.437 & -0.119 & 0.230 & 0.957 & $0.485^{* *}$ \\
\hline IFW & 0.061 & -0.062 & -0.056 & -0.028 & 0.001 & -0.668 & -0.130 & 0.230 & 0.958 & $0.306^{*}$ \\
\hline
\end{tabular}

DFFL - Days to first flowering ( DAS), FLPP - Flowers per plant, PHFH - Plant height at first harvest $(\mathrm{cm})$, BPP - Branches per plant, PT - Pericarp thickness (mm), FPP - Fruits per plant, FL Fruit length $(\mathrm{mm})$, FD - Fruit diameter $(\mathrm{mm})$, IFW - Individual fruit weight (g), YPP - Yield per plant $(\mathrm{Kg})$ and $\mathrm{R}=$ residual effect. 
Plant height at first flowering had positive direct effect (0.112) on yield per plant. This character showed negative indirect effects via days to first flowering, pericarp thickness, fruit diameter and individual fruit weight and positive indirect effects via flowers per plant, branches per plant, fruits per plant and fruit length. Positive correlation (0.086) between plant height at first flowering and yield per plant was the cumulative contribution of these direct and indirect effects. Branches per plant had positive direct effect (0.067) on yield per plant, whereas negative indirect effects were observed via days to first flowering, thickness of the pericarp, fruit diameter, and individual fruit weight. Positive indirect effects were found via flowers per plant, plant height at first flowering, fruits per plant and fruit length. Positive correlation (0.162) between branches per plant and yield per plant was the cumulative contribution of these direct and indirect effects. Verma and Sarnaik (2000) observed that number of branches per plant exhibited positive direct effect on yield. Pericarp thickness showed positive direct effect $(0.426)$ on yield per plant. Indirect effects via days to first flowering, plant height at first flowering, branches per plant, fruit length and fruit diameter were negative. Indirect effects via flowers per plant and individual fruit weight were positive but very poor. Positive correlation (0.169) between pericarp thickness and yield per plant was the cumulative contribution of these direct and indirect effects. Fruits per plant had positive direct effect (0.980) on yield per plant. Indirect effects via days to first flowering, thickness of the pericarp, fruit diameter and individual fruit weight were negative. Indirect effects via flowers per plant, plant height at first flowering, branches per plant and fruit length were positive. Dhankar et al. (2001), Verma and Sarnaik (2000), Mageswari et al. (1999) and Yadav and Singh (1998) found that fruits per plant had the highest positive direct effect on yield. High direct effect (1.7) of the number of fruits per plant on yield was also reported by Islam and Khan (1991) in a study with 12 exotic tomato genotypes. Emphasis should therefore, be given on this trait as one of the most vital yield components for contribution to the final yield. Fruit length had negative direct effect (0.141) on yield per plant. Indirect effects via days to first flowering, flowers per plant, Pericarp thickness, fruit diameter and individual fruit weight were positive. Indirect effects via plant height at first flowering, branches per plant, and fruits per plant were negative. Positive significant correlation (0.788) between fruit length and yield per plant were the cumulative contribution of these direct and indirect effects.

Fruit diameter had positive direct effect (0.230) on yield per plant. Positive indirect effects were found via days to first flowering and negative indirect effects via flowers per plant, plant height at first flowering, branches per plant, pericarp thickness, fruits per plant and fruit length. These direct and indirect effects were contributed to positive significant correlation $(0.485)$ between fruit diameter and yield per plant. Individual fruit weight had positive direct effect (0.958) on yield per plant. Indirect effect via days to first flowering, pericarp thickness and fruit diameter was found positive. On the other hand negative indirect effects were found via flowers per plant, plant height at first flowering, branches per plant, height at first flowering, branches per plant, fruits per plant and fruit length were found. Positive significant correlation (0.306) between individual fruit weight and yield per plant was contributed by these direct and indirect effects in both sowing. Gorbatenko and Gorbatenko (1985) studied path analysis of economically useful characters of tomato and observed that single fruit weight had an appreciable direct effect on yield per plant. Similar result was obtained by Alam et al. (1988) and Islam and Khan (1991) in tomato. From the path analysis it may be pointed out that individual fruit weight might be the most potential yield contributing trait for higher yield of tomato. The residual effects appeared to be considerably low (0.183) which indicated that the characters included in this study explained almost all variability towards yield. 


\section{REFERENCES}

Agong, S. G., S. Schittenhelm and W. Friedt. 2008. Genotypic variation of Kenyan tomato (Lycopersicon esculentum L.) germplasm. PGR Newsletter, FAO Biodiversity, 123, pp 61-67.

Ahmed, K. U. 1976. "Phul Phal O Shak Shabji (in Bangla)". 2nd Edition, Alhaj Kamaluddin Ahmed, Banglow No. 2, Farm Gate, Dhaka, Bangladesh. p. 470.

Alam, S. U., Q. N. Ahmed and M. M. Ali. 1988. Correlation and path coefficient analysis for some characters in tomato. Bangladesh J. Pl. Breed. Genet. 1 (1-2): 42-46.

Bai, Y. and P. Lindhout. 2007. Domestication and breeding of tomatoes: what have we gained and what can we gain in the future. Ann. Bot. 100(5): 1085-1094.

BBS. 2008. Yearbook of Agricultural Statistics of Bangladesh. Planning Division, Ministry of Planning, Govt. of the People's Republic of Bangladesh, Dhaka, Bangladesh, p. 147.

Chowdhury, B. 1979. Vegetables. 6th Edition, The Director, National Book Trust, New Delhi, India. $46 \mathrm{p}$.

Dewey, D. R. and K. H. Lu. 1959. A correlation and path coefficient analysis of components of crested wheat grass seed production. Agron. J. 51: 575 - 581.

Dhankar, S. K., B. S. Dhankhar and N. K. Sharma. 2001. Correlation and path analysis in tomato under normal and high temperature conditions. Haryana J. Hort. Sci. 30(1-2): 89-92.

Gorbtenko, E. M. and I. Y. U. Gorbtenko. 1985. Path analysis of economically useful characters in tomato. Tsitologiya Genetika. 19(3): 206-210.

Hanson, C. H., H. P. Robinson and R. E. Comstock. 1956. Biometrical studies of yield in segregating populations of Korean Lespedeza. Agron. J. 48: 268-272.

Harer, P. N., D. B. Lad and T. J. Bhor. 2003. Correlation and path analysis studies in tomato. J. Maharashtra Agric. Univ. 27(3): 302-303.

Haydar, A., M. A. Mandal, M. B. Ahmed, M. M. Hannan, R. Karim, M. A. Razvy, U. K. Roy and M. Salahin. 2007. Studies on genetic variability and interrelationship among the different traits in tomato (L. esculentum Mill.). Middle-East J. Sci. Res. 2(3-4): 139-142.

Islam, M. S. and S. Khan. 1991. Variability and character association in tomato (Lycopersicon esculentum Mill). Bangladesh J. Pl. Breed. Genet. 4(1-2): 49-53.

Johnson, H. W., H. F. Robinson and R. E. Comstock. 1955. Estimation of genetic and environmental variability in soybeans. Agron. J. 47: 314-318.

Jenkins, J. A. 1948. The origin of cultivated tomato. Econ. Bot. 2: 379.

Mageswari, K., S. Natarajan and S. Thamburaj. 1999. Causal influence of component traits on yield in hybrids of tomato. South Indian Hort. 47(1-6): 179-181.

McGiffen, M. E. Jr., D. J. Pantone and J. B. Masiunas. 1994. Path analysis of tomato yield components in relation to competition with black and eastern black nightshade. J. American Soc. Hort. Sci. 1119(1): 6-11.

Mohanty, B. K. 2002a. Variability, heritability, correlation and path coefficient studies in tomato. Haryana J. Hort. Sci. 31(3-4): 230-233.

Mohanty, B. K. 2002b. Studies on variability, heritability, interrelationship and path analysis in tomato. Ann. Agric. Res. 23(1): 65-69.

Prasad, V. S. R. K. and M. Rai. 1999. Genetic variation, component association and direct and indirect selections in some exotic tomato germplasm. Indian J. Hort. 56(3): 262-266.

Singh D. N., A. Sahu and A. K. Parida. 1997. Genetic variability and correlation studies in tomato (Lycopersicon esculentum Mill.). Environ. Ecol. 15(1): 117-121.

Singh, P., R. K. Singh and B. C. Saha. 1989. Correlation and path analysis in tomato (Lycopersicon esculentum Mill.) Ann. Agric. Res. 10(2): 120-124.

Verma, S. K. and D. A. Sarnaik. 2000. Path analysis of yield components in tomato (Lycopersicon esculentum Mill). J. Appl. Biol. 10(2): 136-138.

Wright, S. 1921. Correlation and causation. J. Agric. Res. 26: 557-585.

Yadav, D. S. and S. P. Singh. 1998. Correlation and path analysis in tomato. J. Hill Res. 11(2): 207-21. 